\title{
Nursing Personnel' Perception Toward Shared Governance and Its Relation to their Job Empowerment Seham M. El Shal ${ }^{1}$, Nermin M. Eid ${ }^{2}$, Rehab M. Ebrahim ${ }^{3}$
}

\author{
1B.Sc. Nursing Science, ${ }^{2}$ Professor of Nursing Administration, Faculty of Nursing, Menoufia \\ University, ${ }^{3}$ Lecturer of Nursing Administration, Faculty of Nursing, Benha University
}

\begin{abstract}
Shared governance has been proposed as essential to improve quality patient care, contain costs, retain and empower nursing staff. The purpose of the study is to assess the perception of nursing personnel toward shared governance and its relation to their job empowerment. A descriptive correlational design was utilized to meet the aim of this study. The subjects: convenience sample included 220 staff nurses and 60 head nurses at Benha University Hospital. The instruments of data collection were professional nursing shared governance questionnaire and the conditions for work effectiveness questionnaire. Results showed that head nurses perception level were higher versus staff nurses in relation to total shared governance perception. Head nurses perception were higher (33.3\% versus $16.4 \%$ ) than staff nurses in the study setting related to total job empowerment. Statistically, staff nurses had a low level of perception (20.0\%versus none) regarding shared governance and job empowerment in the study setting. There was a highly statistical correlation between shared governance and job empowerment among nursing personnel in the study setting. Conclusions: It was concluded that head nurses perception toward both shared governance and job empowerment was higher than staff nurses in the study setting. Recommendation: updated universal protocols and guidelines about shared governance model must be used in the study setting. In- service training and educational programs must be a continuous process for increasing cognitive abilities of nursing personnel underlying decision making.
\end{abstract}

Key words: Nursing personnel, Perception, Shared Governance, and Job Empowerment.

\section{Introduction}

Shared governance $(\mathrm{SG})$ is defined as a frame work that fully recognizes the role of the nurse as knowledge worker. It delineates the responsibilities of the organization and professional nursing individual. This structure facilitates a collaborative partnership between organization, profession and the staff nurses. It requires nurses to have control over their nursing practice, have professional accountability for quality, competence and knowledge generation necessary to enable the professional work of nursing under shared governance.

Shared governance models provide a structure for nursing personnel to have a voice in decision making, policymaking and the ability to manage their practices with high levels of autonomy. These characteristics provide a basis for professional practice that leads to positive outcomes involving, improved patient and staff participation as well as decreased turnover among staff nurses and managers.

Moreover, shared governance is an organizational commitment aimed to empower staff nurses on the basis of the principles of partnership, equity, accountability and ownership. It includes four types of models, namely; unit based governance, which generally refers to governance derived from a nursing unit; councilor governance, which refers to decisions taken by nurses' councils in hospitals; administrative governance, which 


\section{Nursing Personnel' Perception Toward Shared Governance and Its Relation to their Job Empowerment}

considers executive rule as leadership to smaller nurse councils, Congressional governance, which considers that all nursing personnel work to form responsible reservoirs to guide practice.

Empowerment has different definitions according to different employee culture and situation. Empowerment is defined as a concept or as managerial skills in a work place. Others defined empowerment as an interpersonal process with the right information, support, resources and environment, enabling greater personal capacity and effectiveness in defining and achieving organizational goals.

Empowerment involves more than delegation of authority. It involves nursing personnel perception of competence, self-determination, meaning and impact. Psychologically empowered nursing personnel are confident in their abilities, have control over their work, feel that their job requirements are consistent with their values and beliefs and feel that they affect the organization.

Empowered nursing personnel create an environment in which staff nurses feel empowered. Staff nurses and managers must have access to adequate information, resources and support to work with empowerment. Empowered nurse managers facilitate an environment in which staff nurses feel empowered.

Shared governance model is one of the strategies that have been utilized to empower and improve nurses' working level of satisfaction in magnet hospitals. Shared governance is a dynamic process for achieving organizational effectiveness by promoting decision making and accountability for practice through empowerment.

\section{Significance of the Study}

Creating a shared governance culture in hospitals allow nurses to be actively involved with administration in decision influencing practice and enhance decentralization which will lead to make organizational structure and professional practice more complimentary. Applying shared governance framework claimed to improve delivery of quality of care, develop collaborative relations between health care professionals, improve their quality of care and over all clinical effectiveness, increase staff confidence and increase nurses performance (Altimier,2015). High levels of empowerment are related to organizations that have strong shared governance models (Agnes, 2011). So that this study was conducted to assess nursing personnel perception toward shared governance and its relation to their empowerment at Benha University Hospital.

\section{Purpose of the Study}

The purpose of this study was to assess the perception of nursing personnel toward shared governance and its relation to their job empowerment through the following objectives:

1) Assessing the level of perception toward shared governance among nursing personnel in the study setting.

2) Assessing the nursing personnel job empowerment level in the study setting.

3) Assessing the relation between shared governance and job empowerment among nursing personnel in the study setting.

\section{Research questions}




\section{Nursing Personnel' Perception Toward Shared Governance and Its Relation to their Job Empowerment}

1) What is the nursing personnel level of perception toward shared governance in the study setting?

2) What is the nursing personnel job empowerment level in the study setting?

3) Is there a relation between shared governance and job empowerment among nursing personnel in the study setting?

\section{Methods design}

A descriptive correlational research design was utilized to conduct this study.

\section{Setting}

The study was conducted in Benha University Hospital. It was conducted in medical (17units), general (6units), pediatrics (4units), cardiology (1unit), nephrology (1unit), cardio thoracic (1unit) psychiatric (1unit), dermatology (1unit), chest (1 unit), rheumatology (1unit), general surgery units (2 units for females and 2units for males), urology (2units), ENT (1unit) , orthopedic (3units), neurology (1unit), ophthalmology(1 unit), obstetrics (1 unit).

\section{Sampling}

A convenience sample was taken from all departments at Benha University Hospital. It included 220 staff nurses and 60 head. They were selected from General departments (55 nurses and 12 head nurses, pediatrics (20 nurses and 8 head nurses), cardiac (10 nurses and 2 head nurses), Nephrology (9 nurses and 2 head nurses), cardio thoracic ( 9 nurses and 2 head nurses), psychiatric (8 nurses and 2 head nurses), dermatology (6 nurses and 2 head nurses), chest(10 nurses and 2 head nurses),rheumatology(11 nurses and 2 head nurses), general surgical female departments (15 nurses and 4 head nurses), general surgical male departments(11 nurses and 4 head nurses), urology(10 nurses and 4 head nurses ), ENT( 7 nurses and 2 head nurses), orthopedic(12 nurses and 6 head nurses), neurology(11 nurses and 2 head nurses) ophthalmology(7 nurses and 2 head nurses), obestatrics 99 nurses and 2 head nurses).

Instruments:

Two instruments were used:-

Instrument one: Professional Nursing Shared Governance Questionnaire. It was developed by Hess and Andreson, (2011). It was adopted by the investigator to assess staff nurses and head nurse's perception toward shared governance. It included two parts:

- Part one: It contained demographic characteristics of staff nurses and head nurses such as age, marital status, educational qualification, years of experience, attendance training course and number of training course.

- Part two: It included (37 items) underlying (6 categories). The first category is participation, (5 items), professional control, (11 items), organizational influence (9 items), official authority (2items), ability (6 items) and finally access to information (5 items).

\section{Scoring system:}

Responses were measured on three points Likert scale. Agree (2points), Disagree (1point) and Uncertain (0point).The scores for each area of the items were summed up and the total divided by the number of the items ,giving a mean score for the part. These scores were converted into a percent score. The total perception score was considered high if the percent score was equal or more than $75 \%$,moderate if the percent score ranged from $60 \%$ $75 \%$, while It was considered low if the percent was less than $60 \%$. 


\section{Nursing Personnel' Perception Toward Shared Governance and Its Relation to their Job Empowerment}

Instrument two: The Conditions for Work Effectiveness Questionnaire: It aimed to assess job empowerment among nursing personnel from their perceptiveness. It included structural empowerment which included 29 items, (opportunity 4 items), support 3 items, resources 3 items, information 4 items, Selfemployment 5 items, responsibility toward work 4 items and participation in work 6 items). (Psychological empowerment which included 12 items, meaning 4 items, impact 2 items, competence 3items and selfdetermination 3 items).

\section{Scoring system:}

Responses were measured on three points Likert scale as follow, (Always 2, Sometimes1 and Never 0). The scores for each area were summed up and the total was divided by the number of the items to provide the score of each part. These scores were converted into a percent score. The total perception was considered high if the percent score was equal or more than $75 \%$, moderate if the percent score was ranged from $60 \%-75 \%$ and low if the percent score less than $60 \%$.

\section{Validity of tools}

Face and content validity were tested by a panel of five experts in the field of nursing administration (3 professor) and community health nursing(2 professors) in the Universities of Benha and Tanta.

\section{Pilot study}

It was conducted on $10 \%$ of the sample (22 nurses and 6 head nurses) to assess tool clarity and applicability. It has also served in estimating the time needed for filling the form. The time needed to complete each questionnaire sheet was 15:20 minute. The study was tested on $10 \%$ The necessary clarification for some statements was done and the final form was developed and made ready for use.

\section{Ethical considerations:}

Approval of the faculty of Nursing Ethical Research Committee was obtained .Nurses and head nurses were informed that a anonymity and confidentiality of data were maintained. Backeting and intuity were used to ensure scientific honesty. A written informed consent was obtained from nurses and head nurses regarding their acceptance to share in the study.

\section{Scientific honesty:}

To ensure scientific honesty, the researcher uses backeting and intuiting to avoid bias.

\section{Procedure:}

1) An official letter was delivered from the Dean of Faculty of Nursing, Banha University to the director of the studied hospital explaining the purpose and methods of data collection.

2) Data collection extended from August 2017 to the end of October 2017.

3) The investigator met the nursing personnel and explained the purpose and methods of data collection.

4) Each nurse started to fill instrument one, then instrument two was provided.

5) Each head nurse started to fill instrument one followed by instrument two.

6) Nurses took 15 to 20 minutes to fill each questionnaire.

7) Data collection was done in the afternoon shift. 


\section{Nursing Personnel' Perception Toward Shared Governance and Its Relation to their Job Empowerment}

\section{Statistical Design}

After completion of data collection , computerized data entry and statistical analysis were fulfilling score using statistical package for social science (SPSS).( Version twenty)

Data are summarizing using:

- Arithmetic mean: as average describing the central tendency of observation.

- Descriptive statistics: In the form of frequencies, percentages, means and standard deviation.

- The number of observations: For each the percentage (for qualitative variables).

- The standard deviation as a measure of dispersion of results around the mean (for quantitative variable).

- Pearson correlation co efficient (R): Was used to investigate score between items.

- Chi- square test $(\chi 2)$ : Is a test used to

Results: study association between two qualitative variables.

\section{The observed difference associated was considered as following:}

Qualitative were compared using qui square test $\left(\chi^{2}\right)$ as the test of significance. The $\mathrm{p}$-value is the degree is significant. Tests of significance were used to compare study groups using the student's t-test. The p- value is the probability that an observed difference is due to chance and not a true difference. Significance were determined by using FET $=$ Fisher Exact Test. A significance level value was considered when $p$-value $\leq$ 0.05 and a highly significance level was considered when $p$-value $\leq 0.001$, while $\mathrm{p}$ - value $>0.05$ indicates non significance results.

Table (1) Demographic characteristics of study subjects $(n=280)$

\begin{tabular}{|c|c|c|c|c|}
\hline \multirow[t]{2}{*}{ Demographic characteristics } & \multicolumn{2}{|c|}{ Staff nurses $\mathbf{n}=\mathbf{2 2 0}$} & \multicolumn{2}{|c|}{ Head nurses $n=60$} \\
\hline & No & $\%$ & No & $\%$ \\
\hline \multicolumn{5}{|l|}{ Age (years) } \\
\hline $20<25$ & 62 & 28.2 & 15 & 25.0 \\
\hline $25<30$ & 67 & 30.5 & 17 & 28.3 \\
\hline $30<35$ & 74 & 33.6 & 22 & 36.7 \\
\hline$\geq 35$ & 17 & 7.7 & 6 & 10.0 \\
\hline Mean \pm SD & \multicolumn{2}{|c|}{$29.43 \pm 4.35$} & \multicolumn{2}{|c|}{$30.18 \pm 4.96$} \\
\hline \multicolumn{5}{|l|}{ Marital status } \\
\hline Married & 185 & 84.1 & 44 & 73.3 \\
\hline Unmarried & 35 & 15.9 & 16 & 26.7 \\
\hline \multicolumn{5}{|l|}{ Experience years } \\
\hline $1<5$ & 80 & 36.3 & 19 & 31.7 \\
\hline $5<10$ & 67 & 30.5 & 25 & 41.6 \\
\hline $10<15$ & 60 & 27.3 & 10 & 16.7 \\
\hline$\geq 15$ & 13 & 5.9 & 6 & 10 \\
\hline Mean \pm SD & \multicolumn{2}{|c|}{$7.89 \pm 4.18$} & \multicolumn{2}{|c|}{$8.13 \pm 4.65$} \\
\hline \multicolumn{5}{|c|}{ Attend training course about shared governance } \\
\hline Yes & 2 & 0.9 & 0 & 0.0 \\
\hline No & 218 & 99.1 & 60 & 100.0 \\
\hline \multicolumn{5}{|c|}{ Numbers of training course $(n=2)$} \\
\hline Two & 1 & 50.0 & 0 & 0.0 \\
\hline Three & 1 & 50.0 & 0 & 0.0 \\
\hline
\end{tabular}




\section{Nursing Personnel' Perception Toward Shared Governance and Its Relation to their Job Empowerment}

Table (1): Illustrates distribution of nursing personnel regarding their demographic characteristics at Benha University Hospital. This table showed that more than one third among staff nurses and head nurses ranged between $30<35$ years old in the study setting .The majority of head nurses were married. More than one third of nurses had $1<5$ years of experience, while nearly half of head nurses had $5<10$ years of experience. According to attending training course, approximately all studied nurses and head nurses did not attend any training courses.

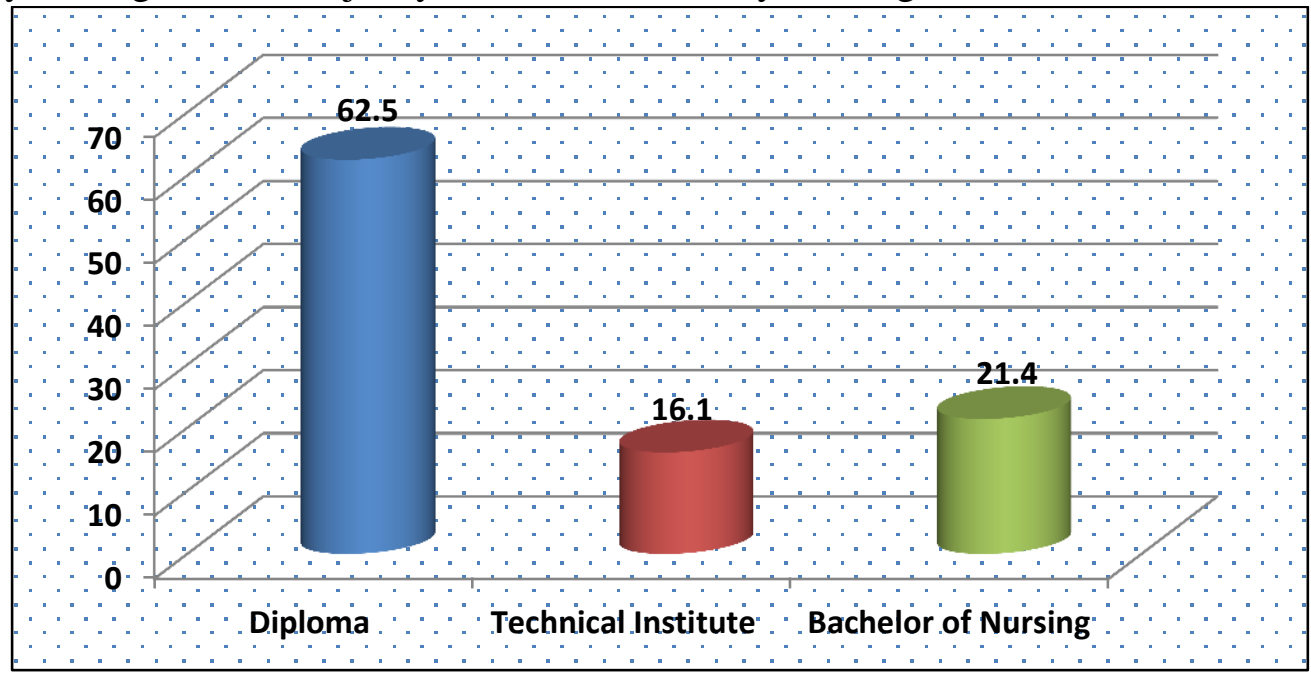

Fig (1) Percentage of nursing personnel according to educational level (280).

Figure (1): Shows distribution of studied nursing personnel according to educational level. More than two third, of staff nurses were nursing diploma, while less than fifth of staff nurses were technical institute. Less than one quarter of head nurses had Bachelor degree in nursing.

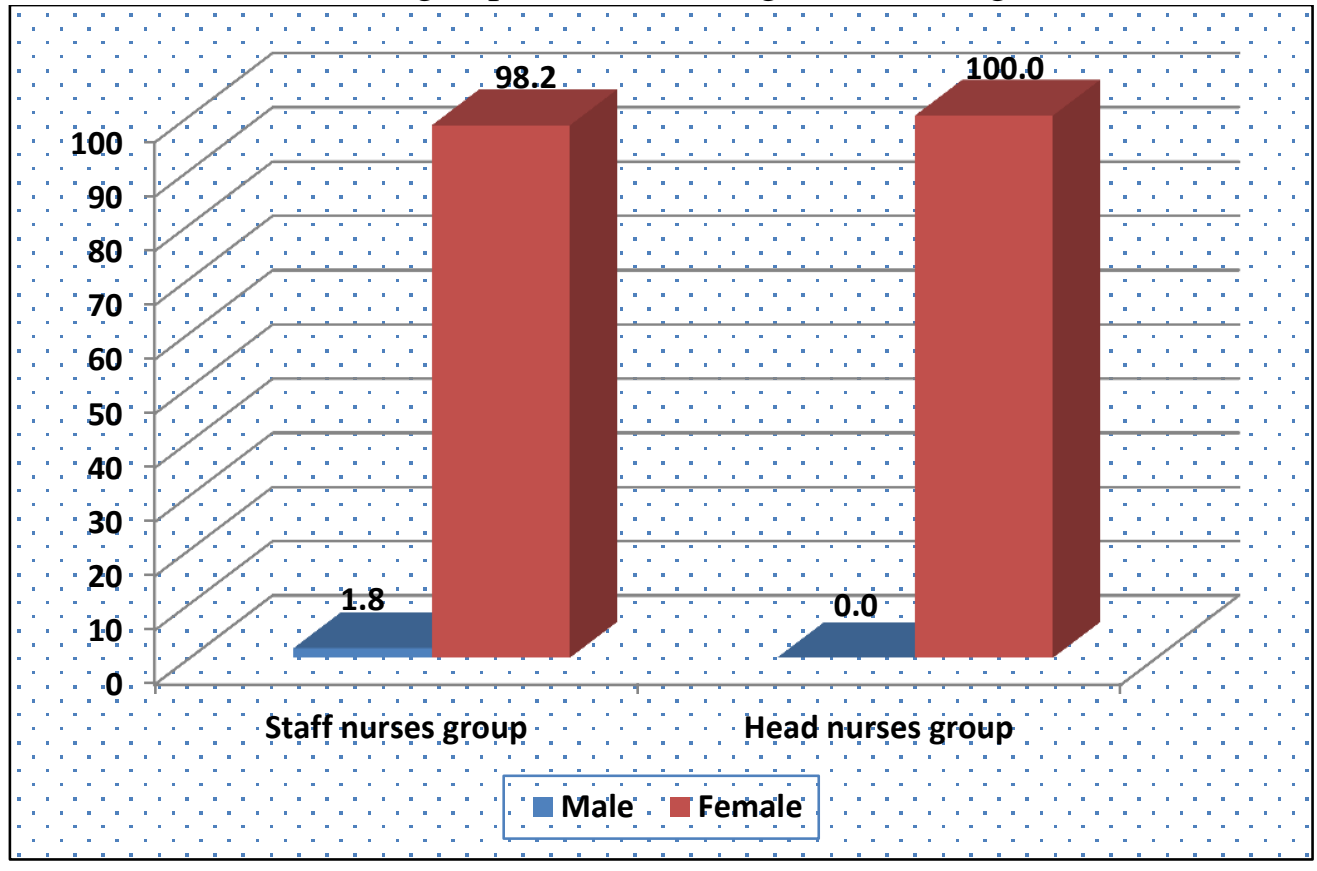

Fig (2) Distribution of nursing personnel according to gender (280). 


\section{Nursing Personnel' Perception Toward Shared Governance and Its Relation to their Job Empowerment}

Figure (2): Shows distribution of studied nursing personnel according to gender. The majority of staff nurses were female, while all the head nurses were female.

Table (2): level of nursing personnel perception about shared governance.

\begin{tabular}{|c|c|c|c|c|c|c|c|c|c|c|c|c|c|c|}
\hline \multirow{3}{*}{$\begin{array}{l}\text { Groups } \\
\text { Shared } \\
\text { governance } \\
\text { items }\end{array}$} & \multicolumn{6}{|c|}{ Staff nurses $n=220$} & \multicolumn{6}{|c|}{ Head nurses $n=60$} & \multirow{3}{*}{$\mathbf{x}^{2} /$ FET } & \multirow{3}{*}{$\begin{array}{c}\text { p- } \\
\text { value }\end{array}$} \\
\hline & \multicolumn{2}{|c|}{ High } & \multicolumn{2}{|c|}{ Moderate } & \multicolumn{2}{|c|}{ Low } & \multicolumn{2}{|c|}{ High } & \multicolumn{2}{|c|}{ Moderate } & \multicolumn{2}{|c|}{ Low } & & \\
\hline & No & $\%$ & No & $\%$ & No & $\%$ & No & $\%$ & No & $\%$ & No & $\%$ & & \\
\hline Participation & 36 & $\overline{c 16.4}$ & 156 & $\overline{70.9}$ & 28 & 12.7 & 21 & 35.0 & 37 & 61.7 & 2 & 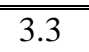 & 12.510 & $0.002 *$ \\
\hline $\begin{array}{l}\text { Organization } \\
\text { al influences }\end{array}$ & 102 & 46.4 & 112 & 50.9 & 6 & 2.7 & 31 & 51.7 & 29 & 48.3 & 0 & 0.0 & 1.978 & 0.372 \\
\hline $\begin{array}{l}\text { Professional } \\
\text { controls }\end{array}$ & 52 & 23.6 & 148 & 67.3 & 20 & 9.1 & 24 & 40.0 & 35 & 58.3 & 1 & 1.7 & 8.692 & $0.013^{*}$ \\
\hline $\begin{array}{l}\text { Official } \\
\text { authority }\end{array}$ & 48 & 21.8 & 162 & 73.7 & 10 & 4.5 & 20 & 33.3 & 34 & 56.7 & 6 & 10.0 & 6.968 & $0.031^{*}$ \\
\hline Ability & 138 & 62.7 & 63 & 28.7 & 19 & 8.6 & 444 & 73.3 & 16 & 26.7 & $\overline{0}$ & 0.0 & 6.062 & $0.048 *$ \\
\hline $\begin{array}{l}\text { Access to } \\
\text { information }\end{array}$ & 79 & 35.9 & 130 & 59.1 & 11 & 5.0 & 32 & 53.4 & 26 & 43.3 & 2 & 3.3 & 5.993 & $0.050 *$ \\
\hline
\end{tabular}

$* \mathbf{P} \leq \mathbf{0 . 0 5}$

** $\mathbf{P} \leq \mathbf{0 . 0 0 1}$ FET $=$ Fisher Exact Test

Table (2): Illustrates perception levels of nursing personnel according to shared governance subtotal score. This table clarified that there was a highly statistical significant difference between head nurses and nurses in participation. for the ability to access information head nurses had higher level of perception than staff nurses $(73.3 \%$ and $53.4 \%$ versus $62.7 \%$ and $35.9 \%)$.

Table(3): Level of nursing personnel perception about job empowerment.

\begin{tabular}{|c|c|c|c|c|c|c|c|c|c|c|c|c|c|c|}
\hline \multirow{3}{*}{$\begin{array}{c}\text { Groups } \\
\text { Items }\end{array}$} & \multicolumn{6}{|c|}{ Staff nurses $n=220$} & \multicolumn{6}{|c|}{ Head nurses $n=60$} & \multirow[b]{3}{*}{$\mathrm{x}^{2} / \mathrm{FET}$} & \multirow{3}{*}{$\begin{array}{c}\text { p- } \\
\text { value }\end{array}$} \\
\hline & \multicolumn{2}{|c|}{ High } & \multicolumn{2}{|c|}{ Moderate } & \multicolumn{2}{|c|}{ Low } & \multicolumn{2}{|c|}{ High } & \multicolumn{2}{|c|}{ Moderate } & \multicolumn{2}{|c|}{ Low } & & \\
\hline & No & $\%$ & No & $\%$ & No & $\%$ & No & $\%$ & No & $\%$ & No & $\%$ & & \\
\hline $\begin{array}{r}\text { Structural } \\
\text { empowerment }\end{array}$ & 43 & 19.5 & 146 & 66.4 & 31 & 14.1 & 19 & 31.7 & 41 & 68.3 & 0 & 0.0 & 11.610 & $0.003^{*}$ \\
\hline $\begin{array}{r}\text { Psychological } \\
\text { empowerment }\end{array}$ & 63 & 28.6 & 150 & 68.2 & 7 & 3.2 & 47 & 78.3 & 13 & 21.7 & 0 & 0.0 & 49.068 & $0.000^{* *}$ \\
\hline
\end{tabular}

*A statistical significant difference $(\mathrm{P} \leq 0.05)$ $(\mathbf{P} \leq \mathbf{0 . 0 0 1}) \quad$ FET $=$ Fisher Exact Test

Table (3):Clarifies distribution of the studied nursing personnel regarding to total level of job empowerment in the study setting. This table showed that there was a highly statistical between head nurses and nurses. It was founded that $78.3 \%$ of head nurses had high psychological empowerment, About
**A highly statistical significant difference

$66.4 \%$ of staff nurses had moderate structural empowerment, while head nurses were $68.3 \%$. The majority of the studied head nurses had higher level of structural empowerment and psychological empowerment than staff nurses. 


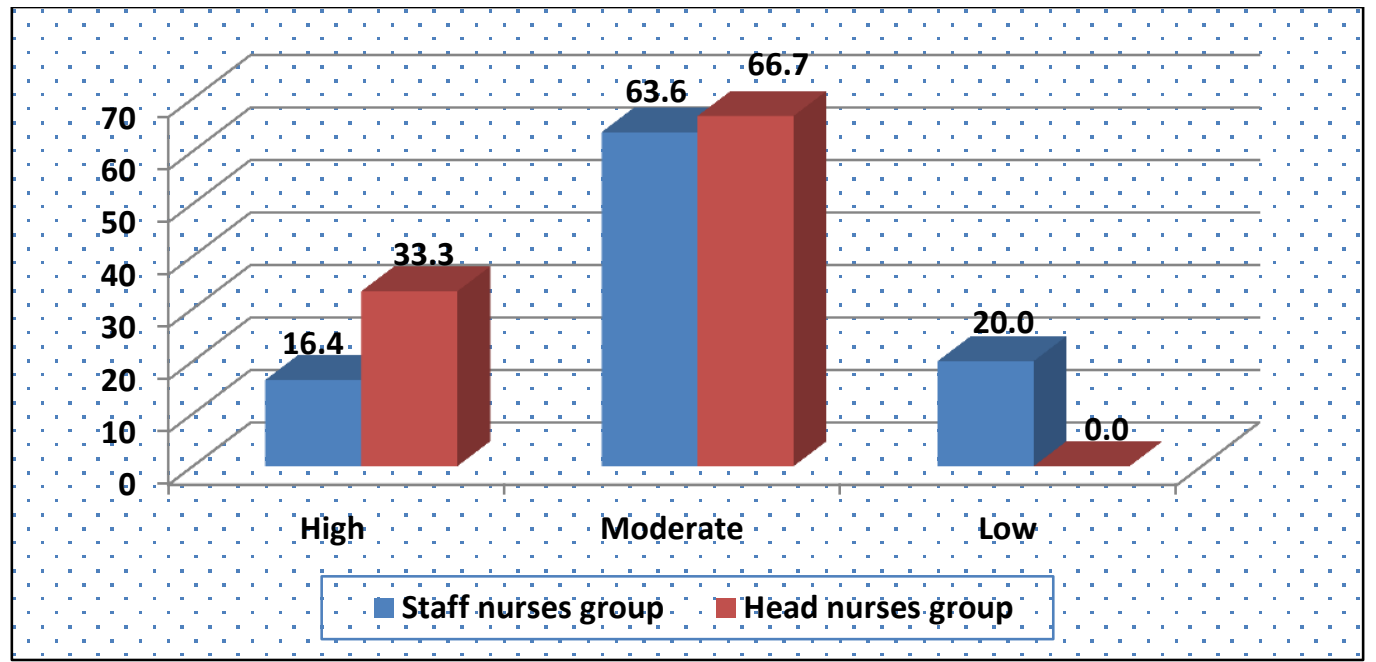

Fig (3) Nursing personnel ' perception regarding of shared governance $(n=280)$.

Figure 3: Shows the level of nursing personnel perception about shared governance. It illustrated that head nurses had higher level of perception regarding Shared Governance than staff nurses.

Table (4) Correlation coefficient between shared governance and job empowerment for staff nurses and head nurses

\begin{tabular}{|c|c|c|c|c|}
\hline \multirow[t]{3}{*}{ Variable } & \multicolumn{4}{|c|}{ Total shared governance score } \\
\hline & \multicolumn{2}{|c|}{ Staff nurses $n=220$} & \multicolumn{2}{|c|}{ Head nurses $n=60$} \\
\hline & $\mathbf{r}$ & $\mathbf{p}$ & $\mathbf{r}$ & $\mathbf{P}$ \\
\hline Total job empowerment score & 0.529 & $0.000 * *$ & 0.578 & $0.000 * *$ \\
\hline
\end{tabular}

** A highly statistical significant difference $(\mathrm{P} \leq 0.001)$

Table (4): shows correlation coefficient between shared governance and job empowerment for staff nurses and head nurses. This table showed that there was a

highly statistical significant correlation
between shared governance and job
empowerment among studied nursing
personnel.

highly statistical significant correlation empowerment among studied nursing personnel.

\section{Discussion}

Shared governance is a compelling way to empower nurses. Allowing nurses to have input regarding their practice provides vital feedback and is a key component in the magnet model for determining a healthy work environment. Nurses want active participation on their unit and in hospital policies and procedures, quality improvement activities, unit changes and meeting agendas (Fraser, 2015).

The present study aimed to assess the perception of nursing personnel toward shared governance and its relation to their job empowerment at Benha University Hospital through; assessing the level of perception toward shared governance among nursing personnel, assessing the nursing personnel job empowerment level and assessing the relation between shared governance and job empowerment among nursing personnel in the study setting.

For perception of nursing personnel about shared governance, the present study revealed that there is a highly statistical significant difference regarding their perception levels of 


\section{Nursing Personnel' Perception Toward Shared Governance and Its Relation to their Job Empowerment}

shared governance items. It was found that one third of staff nurses and more than two thirds of head nurses had level of perception regarding shared governance items, ability and access to information.

The results of the current study agree with Hess, (2011) who conducted a study about slicing and dicing shared governance in and around the numbers revealed that the nursing groups overall high perceptions level of governance fell within the range of a shared governance environment, but decision-making is still controlled primarily by management with some staff input.

For perception of nursing personnel about job empowerment, the present study revealed that there was a statistical significant difference regarding perception levels in the study setting. It was founded that less than two third of staff nurses and more than three quarters of head nurses had high perception regarding structural and psychological empowerment. The majority of studied head nurses had higher level of perception regarding structural empowerment and psychological empowerment than staff nurses.

Manojlovich, (2012)who conducted study about power and empowerment in nursing looking backward to inform the future revealed that structural empowerment had a direct, positive effect on psychological empowerment that, in turn, had a direct positive effect on job satisfaction and a direct negative effect on job strain. Both structural and psychological empowerment was significant predictors of job satisfaction.

From the investigator opinion, to create an empowering work environment for nursing personnel, it is very important that staff nurses and nurse managers are able to obtain organizational support and to provide access to resources and opportunity to empower their staff and to obtain positive related health outcomes.

For the correlation between shared governance and job empowerment, the present study illustrated that there was a highly statistical significant difference in relation to shared governance score with job empowerment score of the studied nursing personnel. The head nurses had a higher score than staff nurses in the study setting.

The results of the current study agree with Barden and Fitzpatrick, (2011) who conducted study about shared governance and empowerment of registered nurses working in hospital setting, who studied the relationship between empowerment and shared governance and found a positive relationship between a nurse's perception of shared governance and empowerment.

\section{Conclusion}

Based on the findings of the study and research hypothesis. It is concluded that head nurses had higher perception about shared governance as well as structural and psychological empowerment. There was a highly statistical significant correlation between shared governance and job empowerment among studied nurses.

\section{Recommendations}

Based on the findings of the current study, the following recommendations can be suggested:-

1) Updated universal protocols and guidelines about shared governance Model must be used in the study setting. 


\section{Nursing Personnel' Perception Toward Shared Governance and Its Relation to their Job Empowerment}

2) Staff nurses and head nurses should be represented in the hospital meetings share and participate in decision making about hospital policies.

3) In- service training program about shared governance and creating positive work environment must be conducted.

4) Researches should be done about strategies to enhance shared governance and job empowerment.

\section{References}

Agnes, M.,(2011). Shared governance and empowerment in registered nurses working in a hospital setting. Nurse Administration Quarterly journal,vol. 35(3), pp:212-218.

Altimier, L., (2015). Shared leadership: leading from the bottom up. Newborn and infant. Nursing Reviews Journal, vol. 6 (1) , pp:35-37.

Bardn, M., Fitzpatrick, J. (2011) .Shared Governance and empowerment of Registered nurses working in hospital etting, Nursing Administration Quarterly, vol.35 (3) , pp:212218 .

Bednarski, D.,( 2013). Shared governance: enhancing nursing practice Nephrology Nursing Journal, vol.36 (6), pp: 511-585.

Brody, A., Ruble, C., (2012). Evidencebased practice councils: Potential path to Staff nurse empowerment and leadership growth. The Journal of Nursing Administration, vol.42 (1), pp: 28-33.

Fraser, S., (2015). Influencing outlook: The importance of nursing staff satisfaction.

Nursing

Management, vol. 41(9),pp: 1216.

Hess, R. (2011). Slicing and dicing shared governance in and around the numbers. Nursing Administration Quarterly, vol.35 (3), pp: 210-225.

Knol , J., Van Linge, R., (2012). Innovative behavior: the effect of structural and psychological empowerment on nurses, vol.65 (20), pp.359-370.

Kristen,M.,Lauren,

H.,(2005).Measuring long term care work: a guide to selected instrument to examine direct care worker experience and outcomes, Institute for the future of aging services.

Laschinger, S., (2001).Workplace empowerment, incivility and burnout: Impact on Staff nurse recruitment and retention outcomes. Journal of Based Practice Expert Interventions. New York: McGraw Hill, vol.3 (7), pp: 100-113.

Manojlovich, M. (2012). A concept analysis of empowerment: It's Relationship to mental health nursing. Journal of Advanced Nursing, vol. 29 (3), pp: 600-607.

McSherry, R., (2012). The pivotal role of managers, leaders and educators in enabling excellence in nursing care.Journal of Nurse Management, vol.20(1), pp:7-19.

Purdy, N., (2014). Effects of work environments on nurse and patient outcomes. Journal of Nursing Management,vol. 18(6), pp:901 913.

Richardson, N., Storr, L., (2010).A comparison of working conditions among Nurses in Magnet and non - Magnet hospitals. The Journal of Nursing Administration, vol.40 (8), pp: 309-315.

Styer, A., (2015). Development of a unit- based practice committee: a form of shared governance. AORNJ, vol. 86(1), pp. 85-100. 